\title{
Financial support of graduate programs in Brazil: quo vadis?
}

A.F. Helene and G.F. Xavier
Departamento de Fisiologia, Instituto de Biociências, Universidade de São Paulo, São Paulo, SP, Brasil

\section{Correspondence}

A.F. Helene and G.F. Xavier Departamento de Fisiologia Instituto de Biociências, USP Rua do Matão, Travessa 14, 101 05508-900 São Paulo, SP Brasil

E-mail: afh@ib.usp.br or gfxavier@usp.br

Research supported by FAPESP, CNPq and CAPES.

Received June 15, 2005

Accepted April 24, 2006

\section{Abstract}

Graduate programs provide the highest level of formal education and thus are crucial for the development of any country. However, official Brazilian data clearly show a dramatic decrease in the number and values of scholarships available to graduate programs in Brazil over the last few years, despite the importance and growth of such programs. Between 1995 and 2004, investment by the Coordenadoria de Aperfeiçoamento de Pessoal do Ensino Superior (CAPES, subordinate to the Ministry of Education and Culture) in funding scholarships, corrected for inflation in the period, actually decreased by $51 \%$. In addition, during the period between 1994 and 2004, there was a loss of about $60 \%$ in the purchasing power of the graduate scholarships provided by CAPES and the National Council for Science and Technology $(\mathrm{CNPq})$. To reverse this trend, we propose the development of sectorial funding for Brazilian graduate programs to guarantee the availability and continuity of financial support for this strategic activity.

\section{Key words}

- Graduate programs

- Scholarships

- Financial support

- PhD program

- Doctoral degree

- Master's degree

\section{"Good planners invest in education"}

\section{Introduction}

The establishment of graduate programs in Brazil has been one of the more successful National initiatives in the last few decades. From the beginning, these graduate programs have contributed to the education of highly qualified investigators and university lecturers, and to the production of knowledge in this country. Graduate programs have educated most of Brazilians effectively engaged in science, technology, innovation, and academia in Brazil. This serious enterprise is promoting a notable change in Brazil through qualified education, and Brazilian authori- ties have made a substantial effort to formally and systematically evaluate our graduate programs (1). Although this evaluation system requires improvement, there is no doubt that it has contributed decisively to the evolution of these graduate programs. Not surprisingly, educational authorities attribute great importance to this level of education for the qualification of human resources.

The current importance of graduate programs in providing scientific, cultural and technological knowledge in any country is undisputed. The ability to produce knowledge and to solve problems is a necessary condition for real national self-determination and for conducting one's own affairs and destiny.

Contrary to what might be expected, given 
the importance of this sector for progress in Brazil, the current lack of explicit and clearcut policies, particularly regarding financial support, is surprising and deserves attention $(1,2)$.

The present study evaluates the official data on financial investment by Brazilian authorities in graduate programs over the last few years, analyzing the apparent policy for this sector, and whether this policy in fact recognizes the contribution of the sector to the economic, cultural and social development of Brazil.

Unfortunately, the official data reveal that the policy regarding financial support lags well behind the importance of the graduate programs themselves. Despite constant growth in the number of students engaged in improving their education through graduate programs, financial investment for this level of education has suffered a real decrease, weakening this critical link in the chain of academic structure, knowledge production and the stimulation of self-competence in the country (see below).

\section{Graduate programs and the production of scientific knowledge in Brazil}

Over the last few decades, Brazilian scientific production, as reported in terms of articles published in indexed journals, has increased substantially. In 2003, Brazilian investigators contributed $1.7 \%$ of the total number of scientific articles published in the world; this corresponds to a $15 \%$ increase compared to 2002, when that contribution was $1.55 \%$. This increase is even more impressive compared to 1996 (when Brazilian contribution corresponded to $0.9 \%$ ), and 1987 (when it was only 0.4\%) (2). Thus, there has been substantial increase in the generation of scientific knowledge. However, this achievement lies well behind what might be expected of a country that contains about $3 \%$ of the world population and with a
Gross Domestic Product corresponding to about $2.8 \%$ of world production (3). In addition, in $1995,65 \%$ of these scientific publications shared authorship with investigators from developed countries (4). Apparently, over the last few years, this percentage has increased (4). What is the significance of such an increase? If it reflects an intellectually independent, national scientific effort to collaborate with international laboratories, we should be satisfied. However, if it reflects dependence on international laboratories, with our national laboratories merely playing a secondary role, performing technical protocols and providing their international counterparts with the data collected, without effective participation in research planning, hypothesis generation, final interpretation and discussion of the data, and without elaborating the articles to be submitted to scientific journals, then we should be concerned.

Brazil stands as the seventeenth country on the list of contributors to world science, which might be considered an adequate ranking. However, this position is questionable since the Brazilian economy is among the ten largest world economies.

A detailed analysis of the authorship of full papers in national and international journals, annals of congresses, books and book chapters by Brazilian investigators reveals 48,800 authors in 1998. While 37,500 of these authors were established investigators (about 77\%), 11,300 were students (about 23\%), most of them graduate students. The number of authors increased to 89,000 in 2003, 52,532 of whom (about 59\%) were established investigators, and 36,385 were mostly graduate students (about 41\%; Figure 1). The number of both established investigators and graduate students participating in the authorship of articles increased between 1998 and 2003 (2). However, while this increase was $40 \%$ for established investigators, it reached $223 \%$ for mostly graduate students. In addition, while the increase in the number of articles pub- 
lished in wide circulation international journals, including student authorship, reached $31 \%$, for established investigators the increase was about $3.6 \%$. Thus, there was clearly a greater increase in the number of student authorships. Even though this increase seems to have been promoted by the Coordenadoria de Aperfeiçoamento de Pessoal do Ensino Superior (CAPES) policy of giving greater credit for papers including students authorship, it emphasizes the critical contribution of the students for the scientific enterprise in Brazil.

It is thus beyond question that Brazilian graduate students have markedly increased their contribution to the production of scientific knowledge in the country, as expressed in terms of published articles. However, it should be remembered that their greatest contribution to the country will take place in the future, when they themselves become established investigators and contribute to the multiplicative effort of educating new graduate students for scientific research and university lecturing.

\section{Financial investments in graduate programs}

Official data show that Federal investment in research and development in Brazil between 1996 and 2004 increased from 2 to 3.7 billion reals (the Brazilian currency is the "real", R\$) (Figure 2), apparently corre-
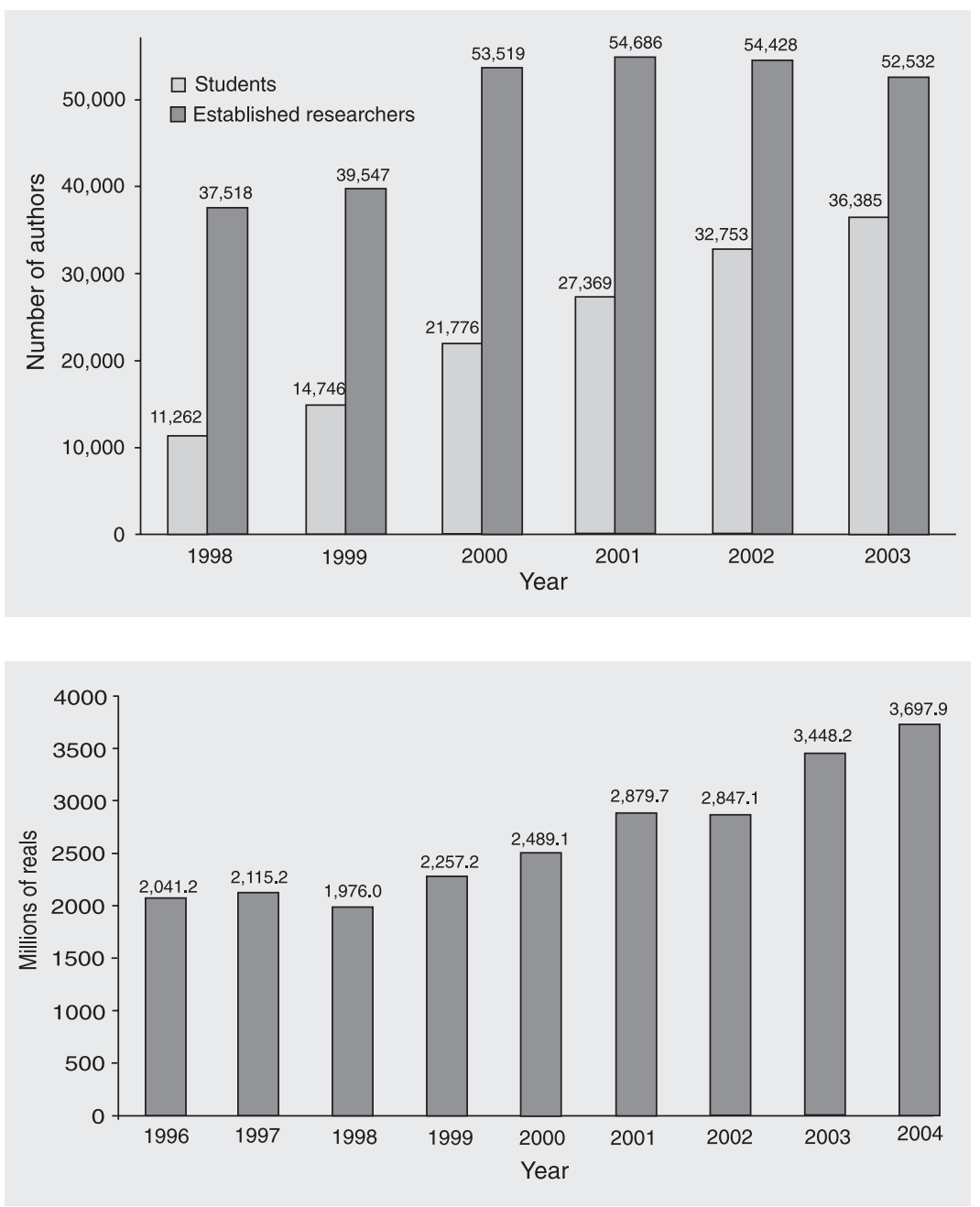

Figure 1. Brazilian authorship of publications, including established investigators and students, between 1998 and 2003 (original data source: Ministry of Science and Technology, http://www.mct.gov.br/estat).
Figure 2. Federal investment in scientific research and development in Brazil between 1996 and 2004 (original data source: Ministry of Science and Technology, http:/ /www.mct.gov.br/estat). 
sponding to an $85 \%$ increase in allocated resources $(2,5,6)$. However, when corrected for inflation using official indexes (e.g., the Consumer Price Index that allows comparison of the relative purchasing power of the currency, like the Brazilian IGP-DI), this figure in fact represents a $25 \%$ decrease in investment (Figure 3) $(2,5,6)$. This is a significant reduction and may be of help to understand some of the problems Brazil is facing regarding funding for its graduate programs.

The budget administered by the Ministry of Science and Technology was R \$1.4 billion in 1999 , increasing to $\mathrm{R} \$ 2.73$ billion in
2003 (Figure 4), suggesting an almost 100\% increase in resources. Likewise, the budget effectively administered by the National Council for Science and Technology (Conselho Nacional de Desenvolvimento Científico e Tecnológico, CNPq, a Federal agency) for scholarships and fellowships increased from $\mathrm{R} \$ 430$ million in 1999 , to $\mathrm{R} \$ 498$ million in 2003 (Figure 4), again suggesting a $15 \%$ increase in investment in scholarships. However, when corrected for inflation using official indexes (e.g., IGP-DI), there was a real increase of only $6 \%$ in the Ministry of Science and Technology budget, and an actual decrease of $38 \%$ in the budget for schol-

Figure 3. Federal investment in scientific research and development in Brazil between 1996 and 2004, corrected for inflation using the IGP-DI, and considering 2002 as the reference point (original data source: Ministry of Science and Technology, http://www.mct.gov.br/ estat).

Figure 4. Ministry of Science and Technology (MCT) budget between 1999 and 2003, and the amount spent on scholarships and fellowships (original data source: Ministry of Science and Technology, http://www.mct. gov.br/estat, and CNPq, http://fomentonacional.cnpq.br/ dmfomento/home/index.jsp).
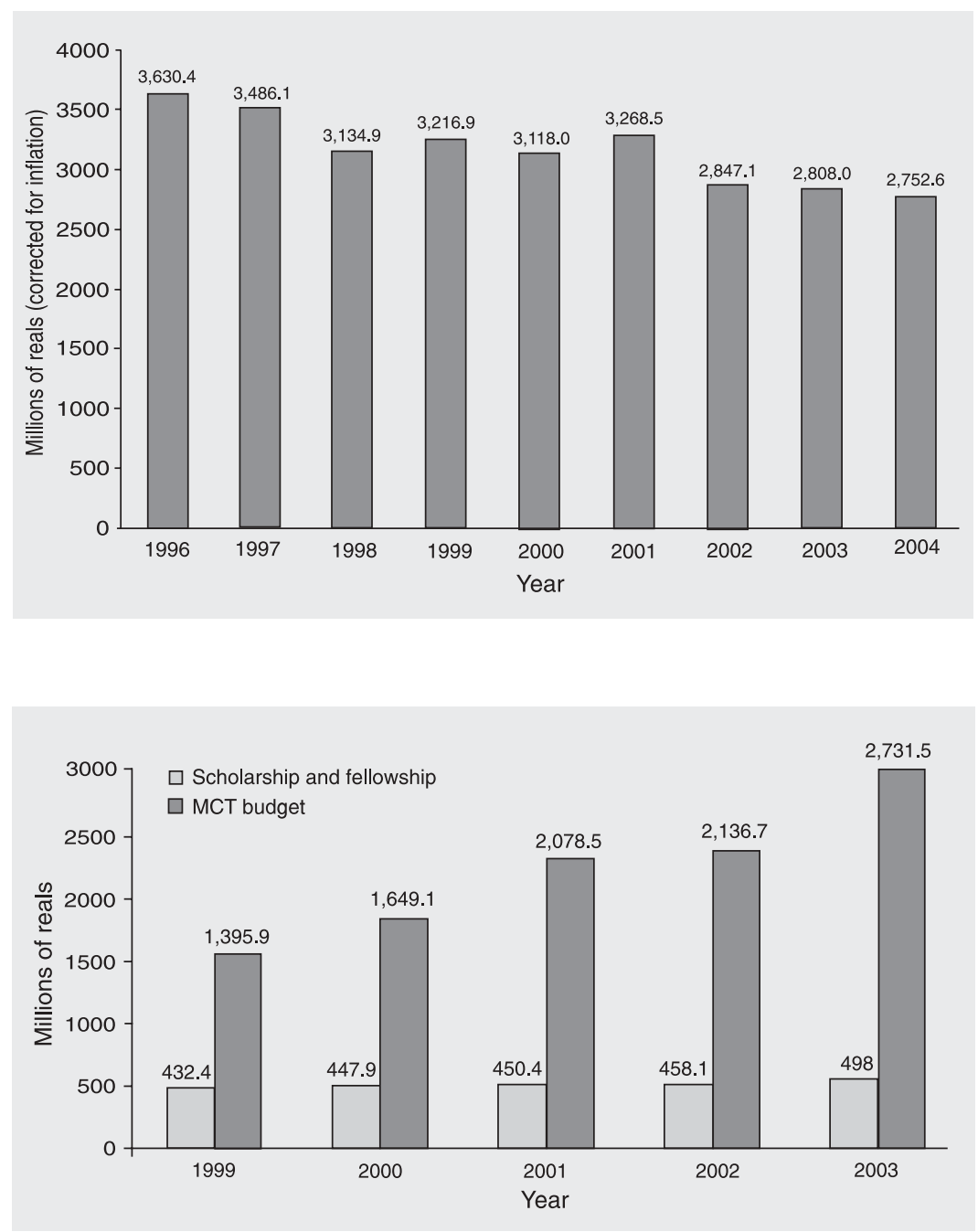
arships and fellowships (Figure 5) $(2,5,6)$. Even more surprisingly, scholarship resources include undergraduate and graduate students, and the resources invested in graduate scholarships decreased about $30 \%$ between 1997 and 2002. When corrected for inflation over this period, there was a $65 \%$ decrease in resources available for scholarships and fellowships (Figure 6) $(2,5,6)$. More recently, from 2003 to 2005 , there was a slight increase in the budget for graduate scholarships from about $\mathrm{R} \$ 150$ million to about $\mathrm{R} \$ 225$ million, representing a nominal increase of $19 \%$ when corrected for inflation (Figure 6). However, considering the period from 1997 to 2004 as a whole, fund- ing actually decreased by $46 \%$ (Figure 6) $(2,5,6)$.

What is the cause of this dramatic reduction in investment in scholarships and fellowships by CNPq? Was it a reaction to the persistent criticism throughout the nineties that $\mathrm{CNPq}$ had become a "scholarship agency", a role perhaps better played by CAPES, another Federal graduate-funding agency subordinate to the Ministry of Education and Culture?

An analysis of the resources invested by $\mathrm{CNPq}$ in scholarships and fellowships is revealing. In 1997, $44.3 \%$ of the resources were invested in graduate scholarships (including Master's and Doctoral scholarships),
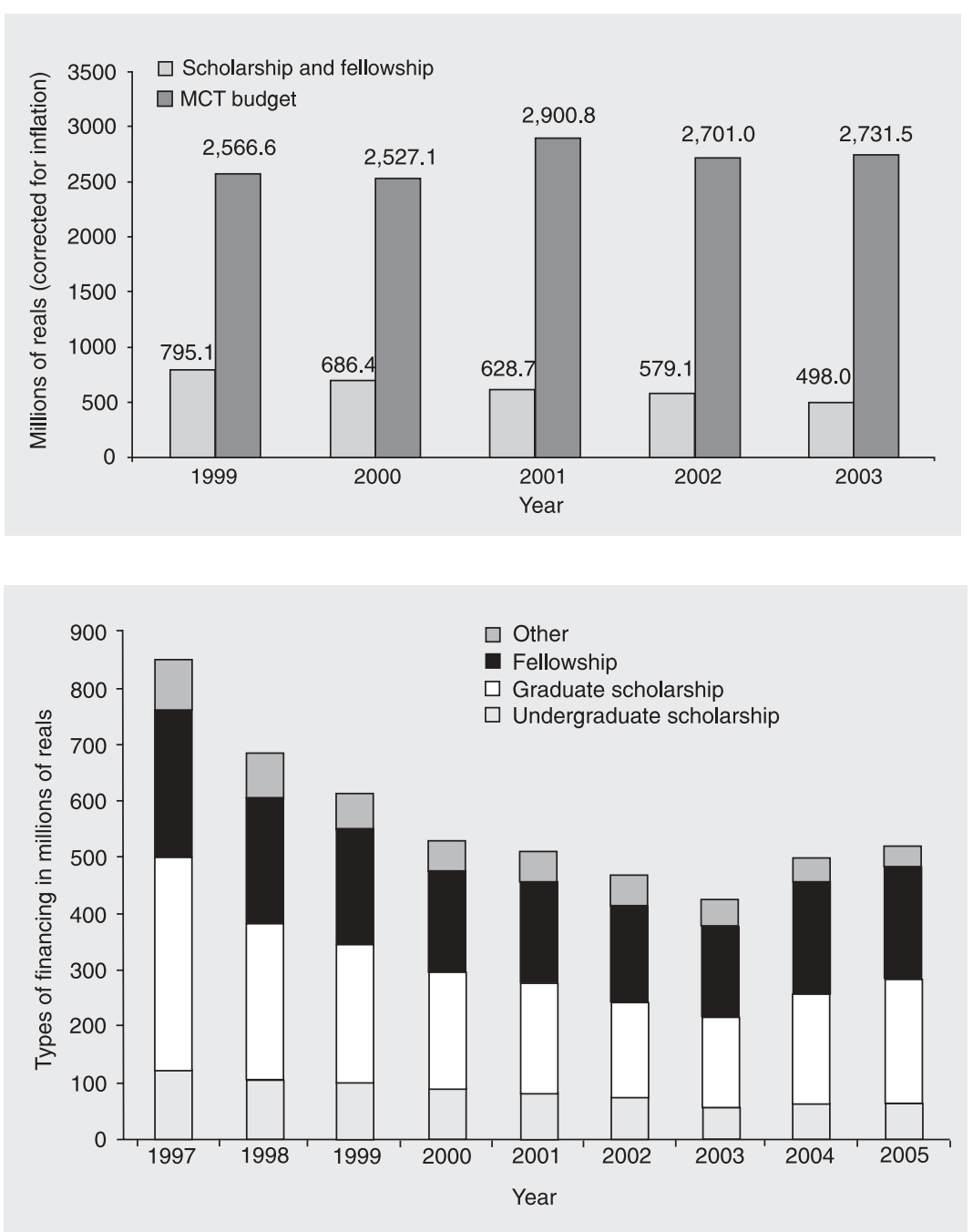

Figure 5. Ministry of Science and Technology (MCT) budget, in reals, between 1999 and 2003, and the amount spent on scholarships and fellowships, corrected for inflation using the IGP-DI, and considering 2002 as the reference point (original data source: Ministry of Science and Technology, http://www.mct.gov. br/estat, and CNPq, http://fomentonacional.cnpq.br/ dmfomento/home/index.jsp).

Figure 6. Distributional support for different types of undergraduate and graduate scholarships, and fellowships between 1997 and 2005 (original data source: CNPq, http://fomentonacional.cnpq.br/dmfomento/home/ index.jsp). 
and in 2002 this percentage decreased to $36.7 \%$ (Figure 6); thus, there was a substantial reduction in investment in scholarships for graduate programs. On the contrary, however, investment in fellowships (for researchers holding Doctoral degrees) showed the reverse; that is, while in 1997 fellowships received $30.5 \%$ of available resources, in 2002 they received $35.6 \%$ (Figure 6 ). Thus, resources were transferred from graduate scholarships to fellowships. From 2003 on, there has been an apparent change in investment trend; there seems to have been an increase in the percentage of investment in graduate scholarships and an apparent decrease in the investment in undergraduate scholarships $(2,5,6)$.

Admitting that these trends reflect a global government policy of maintaining total investment in the graduate programs, with a reduction in the contribution by $\mathrm{CNPq}$ in providing scholarships, and the transfer of this function to CAPES, an increase in investment by CAPES in graduate scholarships might be expected.

Unfortunately, however, this does not seem to be the case. Between 1995 and 2004, investment by CAPES apparently increased 38\% (Figure 7). However, official estimates indicate that inflation during this period amounted to $171 \%$ (IGP-DI). Thus, after correcting for inflation, investment by
Figure 7. Funds spent by CAPES on scholarships between 1995 and 2004 (original data source: CAPES, http://www.capes.gov.br/capes/portal).

Figure 8. Funds spent by CAPES on scholarships between 1995 and 2004, corrected for inflation using the IGP-DI, and considering 2004 as the reference point (original data source: CAPES, http://www.capes.gov.br/ capes/portal).
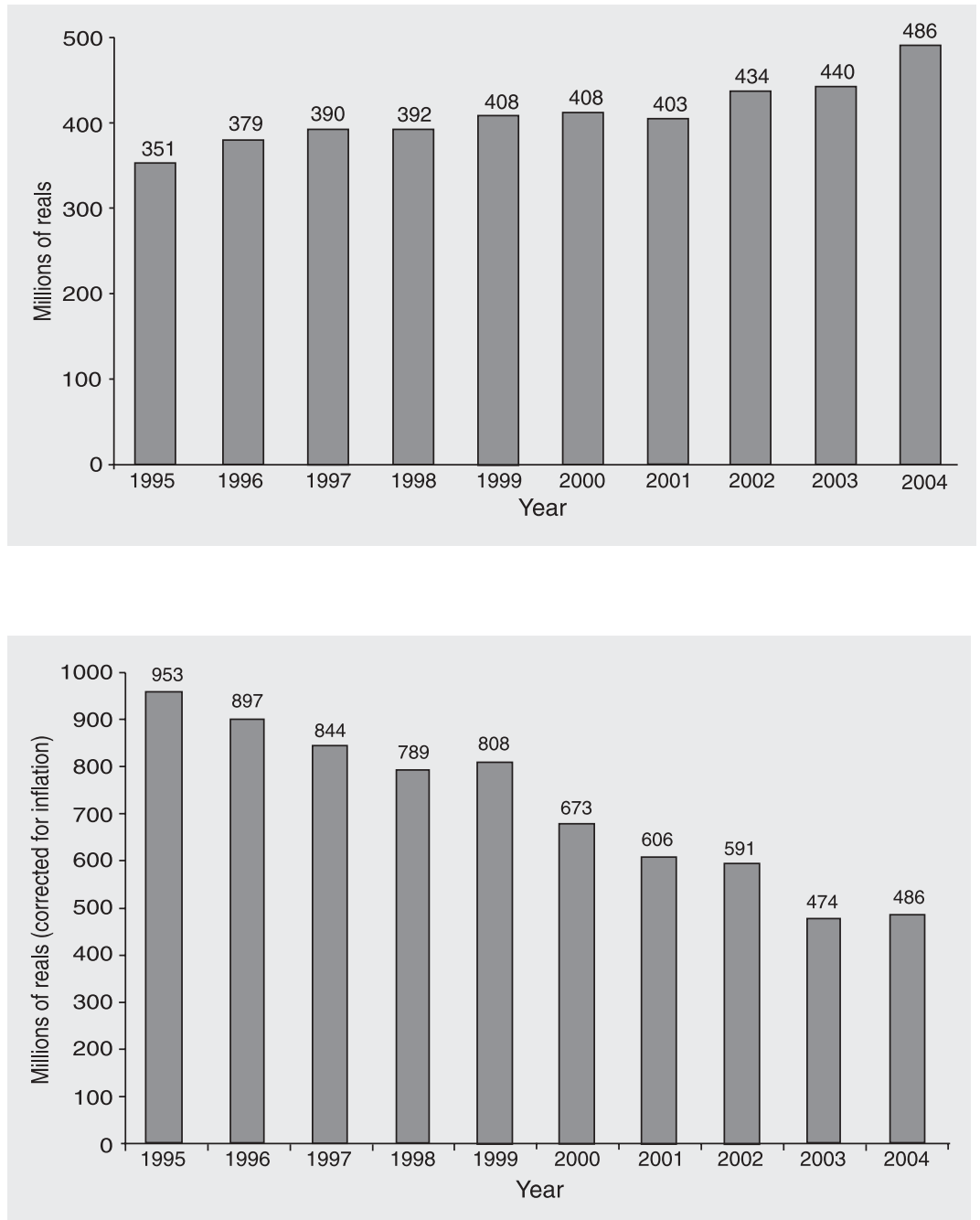
CAPES in funding scholarships actually decreased by $51 \%$ (Figure 8 ). Thus, the reduction in investment for funding scholarships seen for $\mathrm{CNPq}$ was not accompanied by a corresponding increase in investment by CAPES (1).

Taken together, these figures show that there has been a significant reduction in investment in funding graduate scholarships by the Federal agencies (CNPq and CAPES), weakening the Brazilian graduate programs. In São Paulo State, this has been partially and temporarily offset by the São Paulo State Science Foundation (Fundação de Amparo à Pesquisa do Estado de São Paulo, FAPESP), which increased funding for graduate scholarships up to 2000. However, FAPESP, whose funding activities are restricted to São Paulo State, was unable to maintain the pace of investment required by the vacuum left by the Federal agencies. In addition, and perhaps as a reaction to the trend observed for the Federal agencies, from 2000 on FAPESP dramatically changed its policy regarding funding for graduate scholarships. The number of graduate scholarships provided by FAPESP dropped dramatically (Figure 9), exacerbating the lack of funding for graduate scholarships in São Paulo State. For instance, after rigorous analysis of the applications for graduate scholar- ships considered worthy in 2002, FAPESP funded only $25 \%$ of the Master's scholarship applications and only $40 \%$ of the Doctoral applications (7).

In 1997, the University of São Paulo (USP), an institution that confers about 27\% of the Doctoral degrees and $25 \%$ of the Master's degrees given in the country, received 9,000 graduate scholarships (including Master's and Doctoral scholarships); of these, about $22 \%$ were provided by FAPESP, $30 \%$ by CNPq and $48 \%$ by CAPES. In 2000 , after the change in policy for funding graduate scholarships by the Federal agencies and the attempt by FAPESP to compensate, USP still held about 9,000 graduate scholarships; however, about $45 \%$ were provided by FAPESP, $20 \%$ by CNPq and $35 \%$ by CAPES. Differently, in 2002, USP held only 6,000 graduate scholarships, 3,000 less than three years before, despite a substantial increase in the number of graduate students. Not surprisingly, and for the first time since the formal establishment of graduate programs by USP about 35 years ago, there was a decrease in the total number of degrees conferred; that is, the number of graduate students obtaining a Master's or Doctoral degree decreased from 5,361 in 2003, to 4,886 in 2004, a decrease of almost 10\% (data discussed in a meeting of the Curricular Chamber of the Graduate Courses

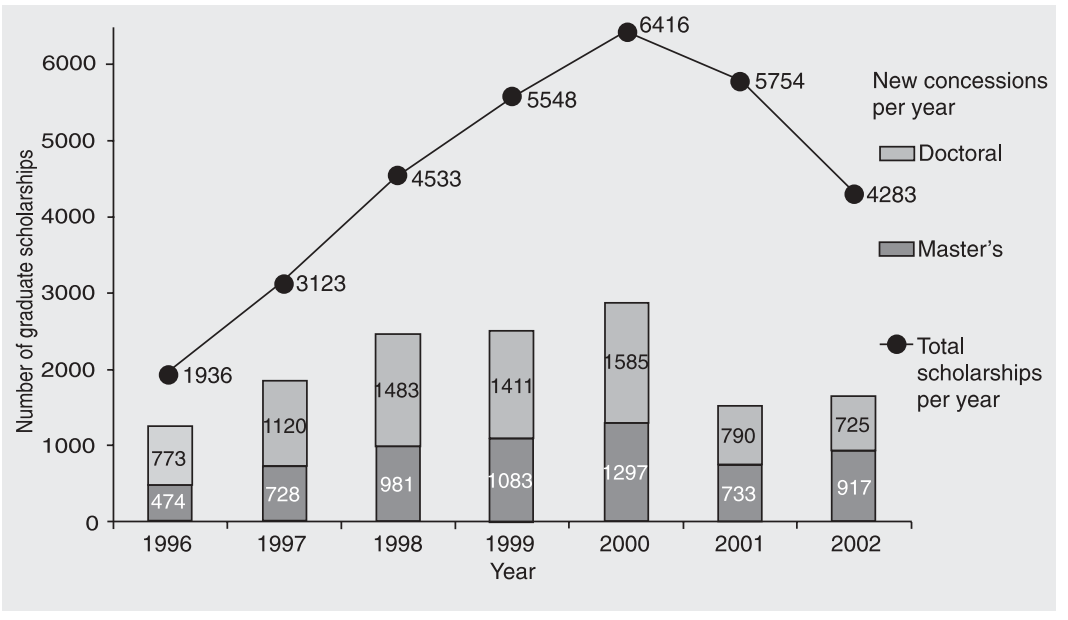

Figure 9. Number of new Master's and Doctoral scholarships awarded by FAPESP, and total number of current graduate scholarships per year between 1996 and 2002 (original data source: FAPESP, http://www. fapesp.br/). 
Council at USP, held in November 9, 2005, including the participation of one of the authors - GFX).

Unfortunately, the reduction in funding of graduate programs has had other consequences. During the period between 1994 and 2004, there was a loss of about $60 \%$ in the purchasing power of the graduate scholarships provided by CAPES and CNPq; for FAPESP this decrease was about 50\% (Figure 10) [the loss of scholarship purchasing power was calculated considering the official Consumer Price Index (Índice Nacional de Preços ao Consumidor), calculated by the Instituto Brasileiro de Geografia e Estatística, an official agency (8)].

Apparently, therefore, the reduction in investment for scholarships was not restricted to the number of scholarships alone but also affected their purchasing power. Taken together, then, these data show that between 1998 and 2004 there was a real reduction of about $70 \%$ in the resources invested in graduate scholarships in the country.

Thus, it seems reasonable to conclude that the Brazilian graduate programs have been abandoned to themselves by the Brazilian authorities.

In this context one might well ask: 1) Will Brazil be able to develop without investing in the education of highly qualified people capable of guaranteeing the intellec- tual independence of the country? It is unquestionable that the graduate programs can efficiently educate human resources for scientific investigation and lecturing at universities. 2) Will the quality of the graduate programs survive and thus contribute to the goal of economic growth and cultural development? 3) Considering the current values of graduate scholarships, will the graduate programs be able to attract qualified undergraduates for graduate education? 4) Will future qualified graduate professionals, the current potential students of the graduate programs, be able to dedicate themselves full time to obtaining their Master's or Doctoral degree, as required by all Brazilian Funding Agencies, while receiving scholarships that are clearly insufficient for their monthly expenses (see Ref. 9)?

There are some 250,000 university lecturers in Brazil. About 33\% of them hold Master's and/or Doctoral degrees (10). Brazil needs Doctoral graduates for both state and private universities (even though the expression "private universities" was used here, most of these institutions are actually "private faculties"). In addition, the substantial expansion of private universities in Brazil (Figure 11) can contribute to the development of the country only if accompanied by quality teaching. And the only way to achieve this is to stimulate the private universities to
Figure 10. Percentage loss of purchasing power of CNPq and CAPES (left panel), and FAPESP (right panel) graduate scholarships between 1994 (CNPq and CAPES) or 1996 FAPESP (1996) and 2006 (calculated using a National Consumer Price Index, the "Índice Nacional de Preços ao Consumidor" (INPC) calculated by the Instituto Brasileiro de Geografia e Estatística, IBGE, an official agency, and considering the scholarship values for 1994 (CNPq and CAPES) or 1996 FAPESP as $100 \%$.

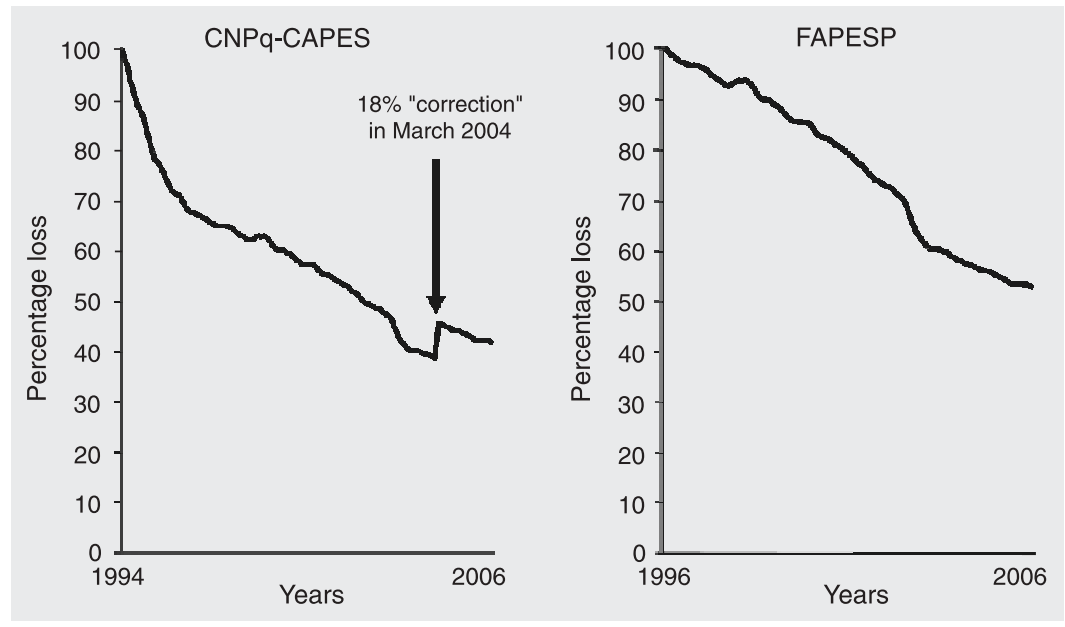


hire qualified university lecturers. The professionals capable of performing this task efficiently in Brazil are those educated by the graduate programs. If this does not occur, we will find ourselves pretending that we are educating our people (perhaps for "statistical purposes"), without actually doing so.

\section{Q uo vadis?}

Our analysis of the official data clearly shows a substantial decrease in the real funding of the graduate programs in Brazil over the last decade; this is manifested not only in the fewer graduate scholarships awarded relative to the increasing number of graduate students but also in the real purchasing power of the scholarship.

Brazil is far from being a knowledge society. The mean period spent at school by Brazilian citizens has increased from 4 to 6 years over the last 20 years. This might be seen as representing an "impressive 50\% increase". However, it is extremely timid when considering how distanced we are from developed countries. We urgently need to increase access to quality schools at all levels of education. Countries whose people do not attain the level of education and knowledge required to adapt to the rapid changes taking place in the world today, and thus

Figure 11. Number of undergraduate students enrolled in state and private universities between 1998 and 2003 (original data source: Instituto National de Estudos e Pesquisas Educacionais Anísio Teixeira, INEP, http://www.inep.gov.br/) capable of finding solutions to their own problems, will be condemned to political, economical and social dependence on those capable of educating their people for science and knowledge production.

Furthermore, providing proper education for those who will be charged with educating our people requires qualified professionals. The education of such professionals cannot be dissociated from 1) qualified universities and research institutions, and 2) their engagement in the process of producing knowledge.

The graduate programs of Brazil have successfully performed this critical role. Located at the top of the educational pyramid, such programs are responsible for the progress of the pyramid as a whole, since they are in a position to identify pathways and alternatives, and to propose actions. In addition, graduate programs are also the main agents for the production of knowledge in Brazil.

Thus, if we aspire to a role for Brazil other than subservience on the world scene, we must urgently reverse the present trend of decreasing financial support for our graduate programs, guaranteeing their growth and improving the quality of education provided to Brazilian students.

Figure 11 shows an increase in the number of university students enrolled in Brazil

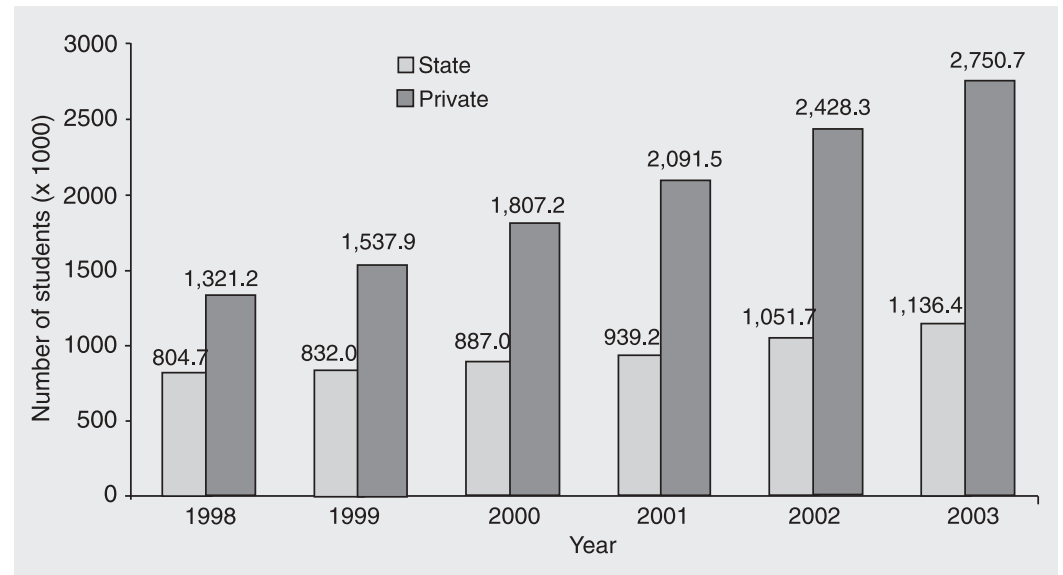


over the last few years. Most of this increase occurred in private universities whose numbers have also increased substantially in recent years (10). Even though the increase in the number of university students may be positive in itself, the fact that it has taken place mainly in private universities is a cause for concern. The hiring of lecturers with a Doctoral degree has been avoided by these institutions (Figure 12) (10), despite the fact that some Doctoral graduates are available, particularly in the south and southeast regions, thus depriving private university students of better teaching. Figure 12 clearly shows that a greater proportion of state uni-
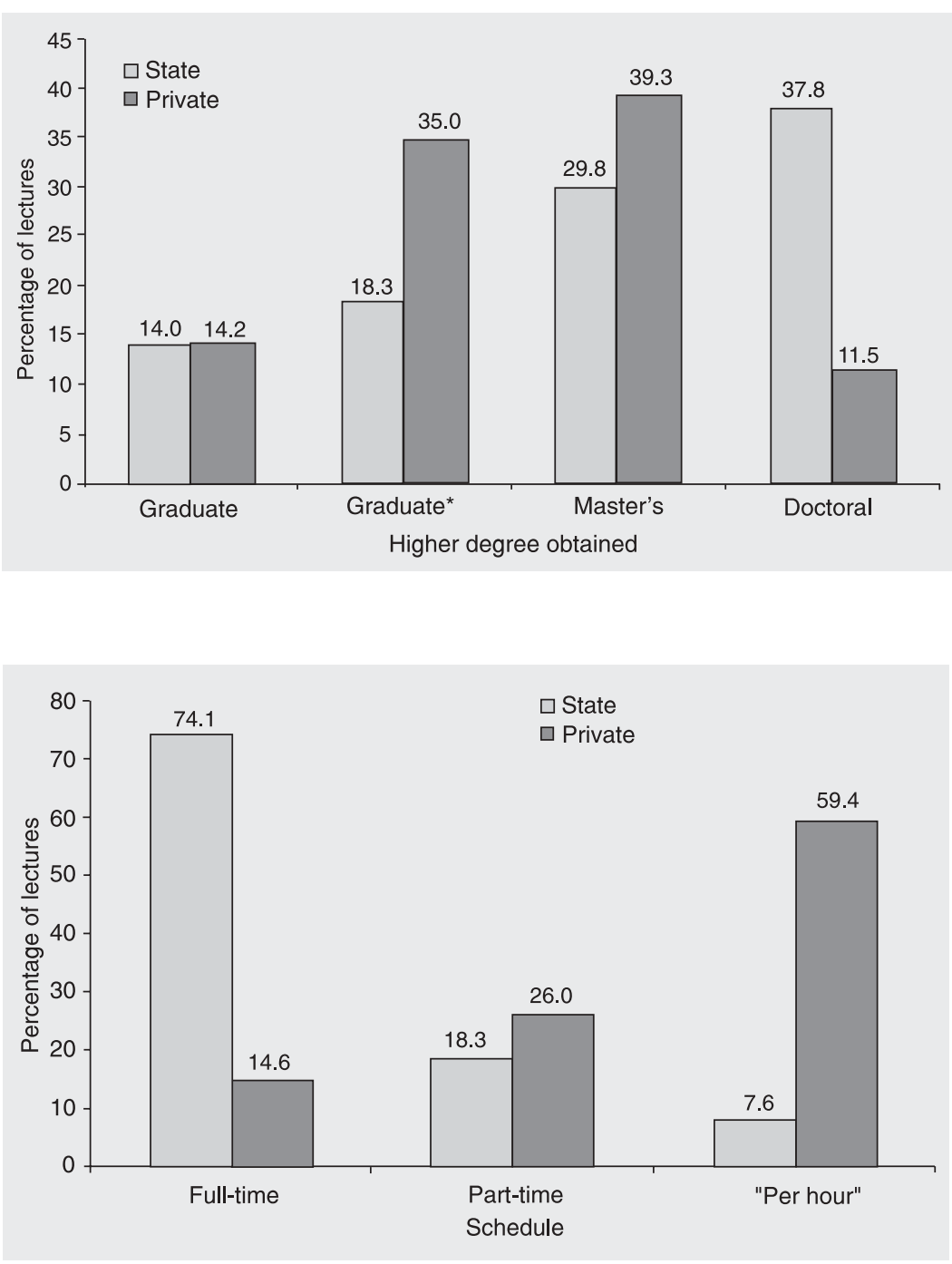

versity lecturers hold Doctoral and/or Master's degrees compared to private university lecturers, only $11.5 \%$ of whom hold a Doctoral degree (10). Furthermore, while lecturers at state universities are usually employed full time (Figure 13) (10), thus being able to conduct scientific research in university laboratories and to assist students outside the classroom, the lecturers at private universities are either part time or mostly, and unfortunately, hired "per hour" (Figure 13) (10), appearing at the university only when actually lecturing in the classroom.

Brazil urgently needs Doctoral graduates to be hired by both state and private univer-

Figure 12. Percentage of lecturers employed by state and private universities as a function of higher degree obtained, calculated based on data available in J une 2003 (original data source: INEP, http://www.inep. gov.br/). *G raduate with 1 year additional study.

Figure 13. Percentage of lecturers employed at state and private universities as a function of work regimen, including full-time, part-time or "per hour" schedules, calculated based on data available in J une 2003 (original data source: INEP, http://www.inep.gov.br/). 
sities. Thus, we must guarantee the availability and stability of the financial support required on a short-, medium- and long-term basis for this enterprise since it is crucial to the development of the nation.

In this context, in addition to an increase in funding by the Ministry of Education and Culture, and the Ministry of Science and Technology, for this strategic sector, we propose the creation of "Sectorial Funds" for the graduate programs ("CT-Pós" in Portuguese) to guarantee continuous and stable support for this activity. The CT-Pós should pursue similar goals and adopt procedures similar to those of other "Sectorial Funds" already functioning in other areas. Thus, the system must 1) adopt a model of transparent management, 2) contribute to reducing regional differences through education and stimulating Doctoral graduates to work in less developed regions, and 3) promote collaboration between universities to improve the qualification of promising professionals who lecture at less qualified universities. Similar to the Sectorial Funds of other areas, the origin of these resources should also be diversified. Some should come from private universities, since, to justify their functioning, these institutions must fulfill the critical goal of providing quality education for which they will need qualified professionals. Other possible sources should include 1) high technology companies, since they benefit from the highly qualified professionals available for hiring, and 2) other Sectorial Funds, given that these currently cannot allocate resources for scholarships.

\section{Technical notes}

IGP-DI. The Fundação Getúlio Vargas (FGV) calculates this index (General Price Index, Internal Availability), which was created to provide estimates concerning public bonds and shares, wholesale prices, food prices, and the cost of living. The IGP aimed at deflating the monthly index of trade evolution. To obtain the IGP the Wholesale Price Index (Índice de Preços por Atacado IPA, in Portuguese), the Consumer Price Index (Índice de Preços ao Consumidor IPC, in Portuguese) and the National Cost of Construction Index (Índice Nacional de Custo da Construção - INCC, in Portuguese) are weighted as 6, 3 and 1, respectively. The DI version plays this role by assigning a lower weight to export products (see http://ecen. com/eee41/eee41e/brazilian_ind.htm\#_ Toc63006759).

\section{References}

1. CAPES Statistics, available at the Home Page. CAPES http:// www.capes.gov.br/capes/portal; 2006.

2. Ministry of Science and Technology. "Indicadores nacionais de ciência e tecnologia", Home Page. MCT http://www.mct.gov.br/estat; 2006.

3. NationMaster http://www.nationmaster.com; 2005.

4. Dietrich CP. Publish and perish, Brazilian scientists' dilemma. Cienc Cult 1998; 50: 15-16.

5. CNPq Plataforma Lattes, "Investimentos do CNPq em CT\&I". CNPq http://fomentonacional.cnpq.br/dmfomento/home/index.jsp; 2006.

6. CNPq. Statistics ("Resenha Estatística") between 1997 and 2002. Brazília: CNPq; 2003.

7. FAPESP http://www.fapesp.br; 2005.

8. IBGE http://www.ibge.gov.br; 2005.

9. Helene AF, Valentinuzzi VS. Brazil needs action rather than words. Nature 2004; 431: 627

10. INEP ("S inopse do ensino superior", 1999-2004). INEP http://www. inep.gov.br/; 2006. 